\title{
Alterations in Nucleolar Structure and Gene Expression Programs in Prostatic Neoplasia Are Driven by the MYC Oncogene
}

\author{
Cheryl M. Koh, ${ }^{*}$ Bora Gurel, ${ }^{*}$ Siobhan Sutcliffe, ${ }^{\dagger}$ \\ Martin J. Aryee, ${ }^{\ddagger \S}$ Denise Schultz, ${ }^{*}$ \\ Tsuyoshi Iwata, ${ }^{*}$ Motohide Uemura, ${ }^{*}$ \\ Karen I. Zeller," ${ }^{,}$Uzoma Anele, ${ }^{*}$ Qizhi Zheng, ${ }^{*}$ \\ Jessica L. Hicks, ${ }^{*}$ William G. Nelson, ${ }^{* \neq \| * * \star \dagger}$ \\ Chi V. Dang, ${ }^{* \neq \uparrow \pi \times \neq \neq \notin \S \S}$ Srinivasan Yegnasubramanian, ${ }^{\neq}$

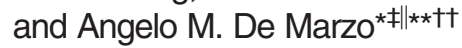

\begin{abstract}
From the Departments of Pathology," Urology," Oncology,* Hematology, ${ }^{\#}$ and Cell Biology, ${ }^{\$ S}$ the McKusick-Nathans Institute of Genetic Medicine, "T The Sidney Kimmel Comprehensive Cancer Center at Johns Hopkins, ${ }^{\ddagger}$ and The Brady Urological Research Institute, ${ }^{+\dagger}$ The Johns Hopkins University, School of Medicine, Baltimore, Maryland; the Department of Biostatistics, ${ }^{\S}$ Johns Hopkins Bloomberg School of Public Health, Baltimore, Maryland; and the Siteman Cancer Center and the Department of Surgery, ${ }^{\dagger}$ Washington University School of Medicine, St. Louis, Missouri
\end{abstract}

Increased nucleolar size and number are hallmark features of many cancers. In prostate cancer, nucleolar enlargement and increased numbers are some of the earliest morphological changes associated with development of premalignant prostate intraepithelial neoplasia (PIN) lesions and invasive adenocarcinomas. However, the molecular mechanisms that induce nucleolar alterations in PIN and prostate cancer remain largely unknown. We verify that activation of the MYC oncogene, which is overexpressed in most human PIN and prostatic adenocarcinomas, leads to formation of enlarged nucleoli and increased nucleolar number in prostate luminal epithelial cells in vivo. In prostate cancer cells in vitro, MYC expression is needed for maintenance of nucleolar number, and a nucleolar program of gene expression. To begin to decipher the functional relevance of this transcriptional program in prostate cancer, we examined $F B L$ (encoding fibrillarin), a MYC target gene, and report that fibrillarin is required for proliferation, clonogenic survival, and proper ribosomal RNA accumulation/processing in human prostate cancer cells. Further, fibrillarin is overexpressed in PIN lesions induced by MYC overexpression in the mouse pros- tate, and in human clinical prostate adenocarcinoma and PIN lesions, where its expression correlates with MYC levels. These studies demonstrate that overexpression of the MYC oncogene increases nucleolar number and size and a nucleolar program of gene expression in prostate epithelial cells, thus providing a molecular mechanism responsible for hallmark nucleolar alterations in prostatic neoplasia. (Am J Pathol 2011, 178:1824-1834; DOI: 10.1016/j.ajpath.2010.12.040)

Alterations in the structure of nuclei are hallmarks of cancer cells. Among these, enlargement, increased number, or altered morphology of the nucleolus all serve as morphological cues for the diagnosis of many premalignant and malignant tumors. ${ }^{1,2}$ For example, it has been documented since at least the 1920s that neoplastic prostate cells are characterized by enlarged, prominent nucleoli. ${ }^{3}$ Further, this is considered a diagnostic morphological alteration in both PIN and adenocarcinoma of the prostate ${ }^{4}$ and nucleolar number and size increase with increasing degrees of prostatic malignancy. ${ }^{5}$

Although a number of potential oncogenic events that are implicated in prostate cancer have been proposed as potential causes of these nucleolar alterations, there is little evidence that known specific molecular changes in prostate cancer drive nucleolar structural and functional alterations in this disease. ${ }^{6}$ For example, it has been suggested that loss of PTEN or the activation of Ets family transcription factors in the mouse prostate results in nucleolar enlargement, ${ }^{7-10}$ yet the effects of these molecular events on nucleoli appear quite modest. Further, it is clear that the

Supported by the Patrick C. Walsh Prostate Cancer Research Fund of which A.M.D. is the Peter J. Sharp Scholar, Prostate SPORE P50CA58236 and The Agency for Science, Technology and Research (Singapore) of which C.M.K is a National Science Scholar.

Accepted for publication December 9, 2010

Supplemental material for this manuscript can be found at $h$ ttp://ajp. amjpathol.org or at doi: 10.1016/j.ajpath.2010.12.040.

Address reprint requests to Angelo M. DeMarzo, M.D., Ph.D., Johns Hopkins University School of Medicine, 1550 Orleans Street, CRB2-144, Baltimore, MD 21231. E-mail: ademarz@jhmi.edu. 
majority of human high-grade PIN lesions, virtually all of which contain marked nucleolar abnormalities by definition, do not harbor loss of PTEN, nor do they overexpress Erg protein. ${ }^{11-13}$

Critical cellular functions performed within nucleoli include ribosomal RNA (rRNA) transcription, processing, and modification (eg, 2'-O-ribose methylation and pseudouridylation), and assembly of the ribosomal subunits. ${ }^{14}$ Ribosomal RNA is a limiting factor for ribosome production and protein synthesis, which are required for cell growth (as in mass) and cell division. The activation of pathways that stimulate protein synthesis are vital elements of tumor cells, and a number of components of the protein synthetic machinery are recognized as bona fide oncoproteins and as targets for cancer treatment. The nucleolus is also involved in the regulation of cell cycle progression and some cellular stress responses. Several nucleolar proteins, such as B23/nucleophosmin, have been associated with cancer, and patients with certain genetic syndromes in which the protein products of the genes involved localize to nucleoli, such as dyskeratosis congenita and Werner, Bloom, and Rothmund-Thomson syndromes, display an increased predisposition to cancer. ${ }^{15,16}$

MYC is one of the most frequently activated oncogenes in human cancers, and its overexpression is commonly observed in various cancer types. ${ }^{17}$ MYC is located on $8 q 24$, a genomic region that is amplified in a subset of aggressive prostate cancers, ${ }^{18,19}$ and elevated MYC mRNA levels have been observed in prostate cancer. $^{20,21}$ Recent studies indicate that MYC protein is markedly overexpressed in the nuclei in most lesions of high-grade PIN, and localized and metastatic prostatic adenocarcinomas. ${ }^{22}$ In vitro, benign prostate cells have been transformed by MYC in a single step. ${ }^{23,24}$ Strikingly, overexpression of MYC in the mouse prostate confers virtually all of the phenotypes associated with the very early stages of prostatic neoplasia, including the development of PIN and invasive adenocarcinomas. ${ }^{25,26}$ These data suggest that MYC plays a critical oncogenic role in the initiation and progression of prostate cancer.

Given the almost ubiquitous overexpression of MYC coinciding with development of PIN during prostate carcinogenesis, we hypothesized that the MYC oncogene may be directly involved in mediating nucleolar enlargement, number, and hyperactive nucleolar function. In support of this, previous reports have shown that overexpression of the Drosophila homolog dMyc causes nucleolar enlargement in fly salivary gland cells. ${ }^{27}$ Further, when targeted to mouse liver, MYC overexpression induced many cellular changes, including nucleolar enlargement. ${ }^{28}$ Also, MYC is known to directly activate transcription of a number of genes whose protein products localize to and function primarily in the nucleolus. ${ }^{29-33}$ However, whether MYC activation directly affects nucleolar architecture and activation of nucleolar gene expression programs in prostate cancer initiation or progression has not been established.

In the current study, we report that MYC activation in vivo is coincident with increased nucleolar size and number at the onset of PIN. In neoplastic prostate cells in vitro, MYC regulates nucleolar number and architecture, and drives a nucleolar program of gene expression. Focusing on $\mathrm{FBL}$, a crucial component of this nucleolar gene expression program involved in rRNA processing, we show that MYC directly regulates the expression of this gene by binding to its promoter region, and that fibrillarin is required for prostate cancer cell proliferation and mature rRNA accumulation. Taken together, these results indicate that MYC overexpression represents a critical mediator of increased nucleolar size, number, and function in PIN and prostatic adenocarcinoma lesions.

\section{Methods and Materials}

\section{Cell Culture}

The human prostate cancer cell lines LNCaP, CWR22rv1, DU145, and PC3, were obtained from the American Type Culture Collection (ATCC, Rockville, MD). MYC-CaP cells were a generous gift from Charles Sawyers. ${ }^{34}$ They were maintained at $37^{\circ} \mathrm{C}$ and $5 \% \mathrm{CO}_{2}$, and supplemented with RPMI 1640 or Dulbecco's modified Eagle's medium with $10 \%$ serum.

\section{Transfections}

Cells were transfected using Oligofectamine or Lipofectamine 2000 (Invitrogen, Carlsbad, CA). Pools containing four small-interfering RNA (siRNAs) against MYC (L-003282; Dharmacon) and fibrillarin (L-011269; Dharmacon, Lafayette, CO) were transfected at a final concentration of $50 \mathrm{nmol} / \mathrm{L}$. As a control in each transfection experiment, cells were transfected with siCONTROL NonTargeting siRNA pool \#1 (D-001810; Dharmacon).

\section{Clonogenic Survival Assays}

Following transfection with siRNA, cells were seeded at low density (500 to 1000 cells/well) using standard plastic (untreated polystyrene) six-well tissue culture plates and incubated for 10 to 14 days. Colonies were fixed with $0.5 \%$ crystal violet/glutaraldehyde. Colonies with more than 50 cells were counted. Four independent knockdown experiments were performed, with each condition done in triplicate each time.

\section{Western Blotting}

Cells and human prostate tissue specimens (20 frozen sections, each $10 \mu \mathrm{m}$ in thickness) were lysed in radioimmunoprecipitation assay buffer. Proteins were electrophoresed and transferred to polyvinylidene fluoride membranes for immunoblotting. Membranes were probed with the antibodies as follows: MYC (\#1472-1; 1:5000 dilution; Epitomics, Burlingame, CA); fibrillarin (ab5821; 1:2000; Abcam, Cambridge, MA); tubulin (CP06; 1:2000; Calbiochem, Gibbstown, NJ); nucleolin (ab13541; 1:2000; Abcam); UBF (sc 13125; 1:1000; Santa Cruz Biotechnology, Santa Cruz, CA); and B23/nucleophosmin (\#18-7288; 1:5000; Zymed, Carlsbad, CA). 


\section{Real-Time Quantitative RT-PCR}

RNA was isolated using Trizol Reagent (Invitrogen, Carlsbad, $\mathrm{CA}$ ), and cDNA synthesized using the RetroScript kit (Ambion, Austin, TX). Quantitative RT-PCR was performed using $i Q$ SYBR Green Supermix (Bio-Rad, Hercules, CA). The primers used are as follows: TBP forward: 5'-CACGAACCACGGCACTGATT-3'; TBP reverse: 5'-TTTTCTTGCTGCCAGTCTGGAC-3'; fibrillarin forward: 5'-TGGACCAGATCCACATCAAA-3'; fibrillarin reverse: 5'-GACTAGACCATCCGGACCAA-3'; pre-rRNA forward: 5'-GAACGGTGGTGTGTCGTTC-3'; pre-rRNA reverse: 5'-GCGTCTCGTCTCGTCTCACT-3'; 5.8s rRNA forward: 5'-ACTCGGCTCGTGCGTC-3'; 5.8s rRNA reverse: 5'-GCGACGCTCAGACAGG-3'; 18s rRNA forward: 5'-GCCTGCTGCCTTCCTTGG-3'; 18s rRNA reverse: 5'-GATGGTAGTCGCCGTGCC-3'; 28s rRNA forward: 5'-AGAGGTAAACGGGTGGGGTC-3'; 28s rRNA reverse: 5'-GGGGTCGGGAGGAACGG-3'. The relative amount of the gene of interest was determined using the $\Delta \Delta C_{\mathrm{t}}$ method, relative to TBP and to the control cells transfected with the nontargeting pool of siRNA. Three independent knockdown experiments were performed, and triplicate quantitative PCR experiments were done for each condition.

\section{Microarray Analysis}

Forty-eight hours after transfection with siRNA against MYC, samples were processed by the Sidney Kimmel Comprehensive Cancer Center's Microarray Core Facility using Agilent's $44 \mathrm{k}$ whole genome array platform (Santa Clara, CA). Analysis was performed using $\mathrm{R}$ and Bioconductor open source software. The gene expression microarray data were preprocessed using Lowess normalization to correct for dye bias. Using gene set enrichment analysis (GSEA), all Gene Ontology (GO) and KEGG (Kyoto Encyclopedia of Genes and Genomes) pathway gene sets were tested for statistically significant enrichment of differentially expressed genes following ranking of individual probes by a moderated $t$-statistic as described. ${ }^{35}$

\section{AgNOR Staining}

Microarray slides were hydrated, steamed for 40 minutes in Target Retrieval Solution (Dako, Glostrup, Denmark), and incubated in 1\% dithiothreitol (Invitrogen) for 15 minutes. Slides were stained in the dark at $37^{\circ} \mathrm{C}$ for 9 minutes with $5 \%$ silver nitrate (Sigma, St Louis, MO) dissolved in $1 \%$ formic acid/0.33\% gelatin (Sigma).

\section{Animal Studies}

The experimental protocol was approved by the Animal Care and Use Committee at Johns Hopkins University, and the animals were cared for in accordance with institutional guidelines. The Lo-MYC transgenic mice used in this study were obtained from the Mouse Repository of the National Cancer Institute Mouse Models of Human Cancer Consortium at $\mathrm{NCl}$ Frederick, MD, and were maintained as previously described. ${ }^{26}$

\section{Electron Microscopy}

Tissues for electron microscopy were obtained from the ventral prostates of Lo-MYC and FVB wild-type mice that were approximately 10 months of age and were fixed in glutaraldehyde and osmium tetroxide and embedded into Epon-Araldite. After routine processing, regions of highgrade PIN and normal were identified after toluidine blue staining of "thick" $(1 \mu \mathrm{m})$ sections, and these regions were subjected to "thin" sectioning and standard staining with lead citrate/uranyl acetate. Thin sections were examined and imaged on a Hitachi7600 (Tokyo, Japan) transmission electron microscope (TEM) equipped with a Dual AMT CCD camera system.

\section{Immunohistochemistry}

Immunohistochemistry was done with the Power Vision+ polyHRP IHC Kit (ImmunoVision Inc, Springdale, AZ). Slides were steamed for 40 minutes in EDTA solution (Zymed) and incubated with rabbit polyclonal anti-fibrillarin antibody (1:50 dilution) for 45 minutes. Poly-HRP-conjugated anti-mouse/rabbit IgG antibody was used as secondary antibody. Staining was visualized using 3,3'-diaminobenzidine (Sigma), and slides were counterstained with hematoxylin.

\section{Chromatin Immunoprecipitation}

Chromatin immunoprecipitation (ChIP) was performed using the rabbit polyclonal anti-MYC antibody (sc-764; Santa Cruz Biotechnology), as previously described. ${ }^{33}$ The primers used are as follows: ChIP fibrillarin forward: 5'-GAGAATCCAGGCTCACTGC-3'; ChIP fibrillarin reverse: 5'-GTTCACAACTCCACGAGTCC-3'; ChIP negative control forward: 5'-AACTCCACATTCCTAAGTGACC-3'; ChIP negative control reverse: 5'-CCAACCCACACCAAGTACC-3'.

\section{Tissues and Tissue Microarrays}

This study was approved by the Johns Hopkins University School of Medicine institutional review board. Tissue microarrays (TMAs) were constructed and evaluated as described. ${ }^{22}$

\section{Analysis of Immunohistological Staining}

Every scanned image from the TMAs was rediagnosed by both B.G. and A.M.D. For image analysis, we used FrIDA (Framework for Image Data Analysis) essentially as described. $^{36}$ Briefly, TMA slides were scanned using the AperioScanScope CS (Vista, CA), and composite images for each TMA spot were generated and imported into the TMAJ software package. For each scanned TMA image, a region of interest mask was manually segmented using polygon tools in FrIDA/TMAJ, and hue, saturation, and value color space segmentation was used to identify the pixels and their intensity for $\mathrm{IHC}$-positive (brown staining) and $\mathrm{IHC}$ negative nuclei (blue staining). Only nuclear staining was considered, and the Fibrillarin Nuclear Area Ratio (brown nuclear area)/(brown + blue nuclear area) and Fibrillarin Score (the summed brown nuclear intensity)/(brown + blue nuclear area) were calculated. Statistical analyses for TMA 
data were performed using SAS (Cary, NC). $P$ values were calculated by linear regression with robust variance estimation to account for the correlation between observations.

\section{Results}

\section{MYC Is Required for the Proliferation/Clonogenic Survival of Prostate Cancer Cells}

MYC is known to be a key regulator of cell proliferation in both normal and cancer cells. ${ }^{37}$ We performed siRNA-mediated depletion of MYC in four different human prostate cancer cell lines, two that are androgen responsive ( $\mathrm{LNCaP}$ and CWR22Rv1) and two that are androgen nonresponsive (DU145 and PC3). We also studied a mouse cell line, MYC$\mathrm{CaP}$, obtained from a MYC-driven prostate cancer. ${ }^{34}$ In all cell lines, MYC protein expression was reduced by approximately $50 \%$ to $90 \%$ by siRNA transfection (see Supplemental Figure S1A at $h$ ttp://ajp.amjpathol.org). Compared to control cells transfected with a nontargeting pool of "scrambled" siRNAs, MYC-depleted prostate cancer cells showed markedly suppressed cell proliferation $(P<0.001$; see Supplemental Figure S1B at http://ajp.amjpathol.org). We also observed, as expected, similar results in MYC-CaP cells (see Supplemental Figure S1B at $h$ ttp://ajp.amjpathol.org). In four of the five cell lines, DNA synthesis was reduced, as measured by the incorporation of 5-ethynyl-2'-deoxyuridine (EdU) $(P<0.05$; see Supplemental Figure S1C at http://ajp.amjpathol.org). There was no increase in apoptosis, as determined by morphological observation. Additionally, the ability to form colonies using clonogenic survival assays was reduced by $65 \%$ to $85 \%$ in cells with siRNA-mediated forced reductions in MYC, as compared to the control in DU145, PC3, and LNCaP cells $(P<$ 0.005 for each), with less of a reduction (28\%) in CWR22Rv1 cells (see Supplemental Figure S1D at $h$ ttp://ajp.amjpathol.org). These results indicate that androgen receptor-positive/androgen-dependent cells (LNCaP, MYC-CaP), androgen receptor-positive/androgen-independent cells (CWR22Rv1), and androgen receptor-negative/androgen-independent cells (PC3, DU145) all require MYC for cell replication, and help establish the relevance of these model systems in studying downstream effects of MYC expression.

\section{MYC Controls Nucleolar Size, Architecture, and Number in Prostate Epithelial Cells}

MYC is known to regulate several nucleolar genes, ${ }^{29-33}$ and marked enlargement of subnuclear structures characteristic of nucleoli are observed using light microscopy in high-grade PIN and adenocarcinoma lesions in the Lo-MYC and Hi-MYC murine models of prostate cancer. ${ }^{25,26}$ The most definitive means to determine whether nuclear structures are nucleoli is by TEM. Thus, we performed TEM on a number of Lo-MYC and wild-type mice. Indeed, we observed markedly enlarged nucleoli in PIN cells from Lo-MYC mice, as compared with wild-type mice (Figure 1A). Since the onset of detectable levels of nuclear MYC protein corresponds precisely with increased apparent nucleolar size in Lo-MYC and Hi-MYC mice, ${ }^{26}$ these findings verify that MYC overexpression alone can lead to increased nucleolar size and number in prostatic luminal cells
A
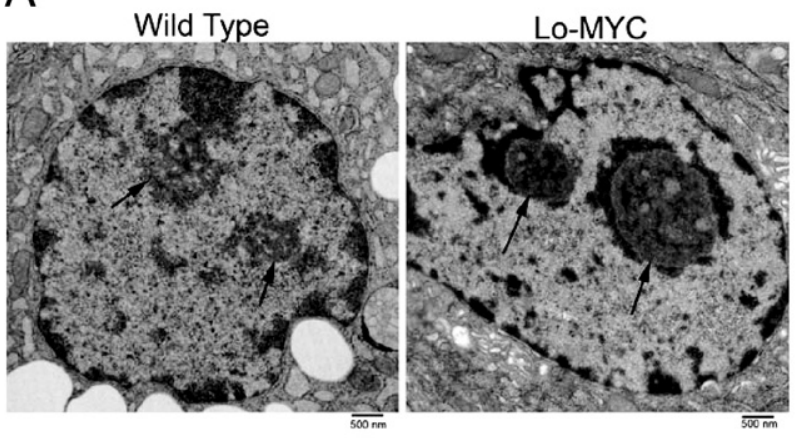

B

PC3

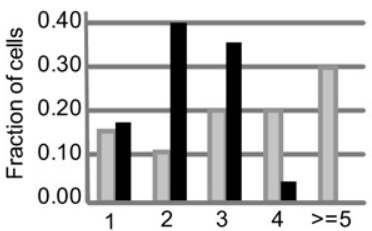

DU145
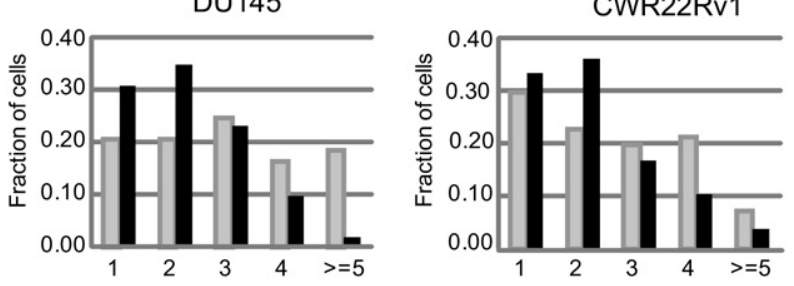

Figure 1. MYC controls nucleolar size and number in prostate cancer cells A: Nucleolar enlargement in a high-grade PIN lesion of Lo-MYC mouse. Electron micrographs showing markedly enlarged nucleolus in a PIN cell from a Lo-MYC mouse (right) as compared with wild-type mouse (left) Arrows indicate nucleoli. Original magnification $\times 8000$. B: Nucleoli were visualized by AgNOR staining and enumerated in 50 to 80 cells after MYC knockdown. Graphs showing the distribution of the number of nucleoli per cell after MYC knockdown (black bars), as compared to control cells (gray bars).

in mice in vivo. Nucleoli are composed of three regions, the fibrillar centers, which house the bulk of the rDNA, the dense fibrillar component, where transcription and rRNA processing occur, and the granular component, where preribosomes are assembled. Indicative of increased nucleolar function, all three components of the nucleoli were generally expanded in these mouse luminal cells overexpressing MYC (Figure 1A). AgNOR staining is a silver staining method that highlights the nucleolar organizer regions of nucleoli. It also correlates with nucleolar activity and the amount of B23/nucleophosmin, nucleolin, UBF, and subunits of RNA Pol I. ${ }^{38}$ We found that nucleolar number and architecture, as visualized by AgNOR staining, were altered in human prostate cancer cell lines following MYC knockdown (Figure 1B, see Supplemental Figure S2A at $h$ ttp:// ajp.amjpathol.org). In general, control-treated cancer cells contained a variable number of highly dispersed nucleoli, often with $>70 \%$ of cells containing three to five or more AgNORstained nucleoli. After MYC knockdown, however, this number generally coalesced into one or two rounded nucleoli per cell (Figure 1B, see Supplemental Figure S2A at http://ajp.amjpathol. org). Taken together, the studies in the Lo-MYC mice verify that MYC overexpression can lead to de novo nucleolar enlargement and increased number in mouse prostate epithelial cells 


\section{A Gene Ontologies (GO)}
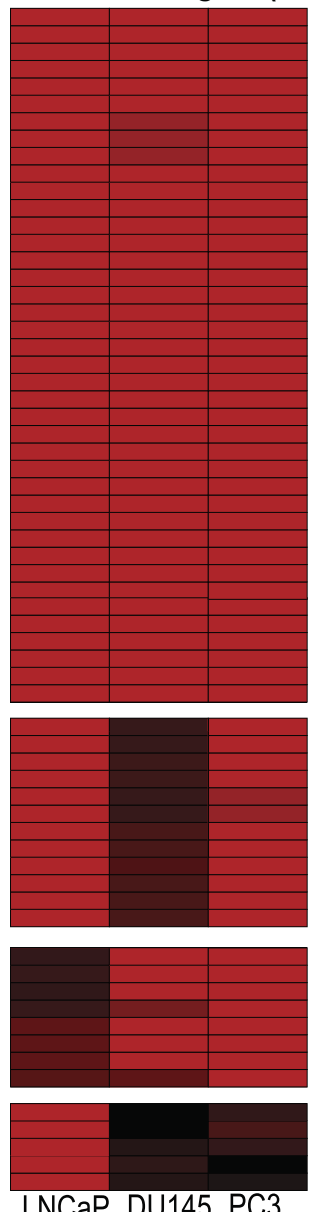

regulation of cyclin-dependent protein kinase activity

DNA replication

nucleoside-triphosphatase activity
nuclear matrix

nuconuclease activity
identical protein bindin

nuclear membrane

DNA repair
DNA replication initiation

nuclear mRNA splicing via spliceosome

nuclearmR
cell cycle

nuclear pore

RNA processing

response to DNA damage stimulus

MRNA transport
unfolded prolein binding

uniolded protein binding
intracellular protein transmembrane transport

intracellular protei

spliceosome

transferase activity

transferase actiily
nucleolus

rRNA processing
nucleotide binding

nucleotide bin
nucleoplasm
nucleus

cytoplasm
mitosis

mitosis
cytosol

methyltransferase activity

ligase activity

mitochondrial inner membrane

mitochondrial matrix

soliceosomal snRNP biogenesis

translation initiation factor activity

hydrolase activity

damaged DNA binding

DNA unwinding during replication

DNA recombination helicase

androgen receptor binding

DNA binding

spindle

protein C-terminus bindin

microtubule
proton-transporting ATPase activity, rotational mechanism

positive regulation of I-kappaB kinase/NF-kappaB cascade

structural constituent of ribosome

mitochondrial inner membrane
nucleoside metabolic process

ribosome

protein processing

TRNA binding
positive regulation of

metal ion binding
zinc ion binding

cell aging
acid-amino acid ligase activity

vesicle-mediated transport 0.00

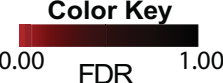

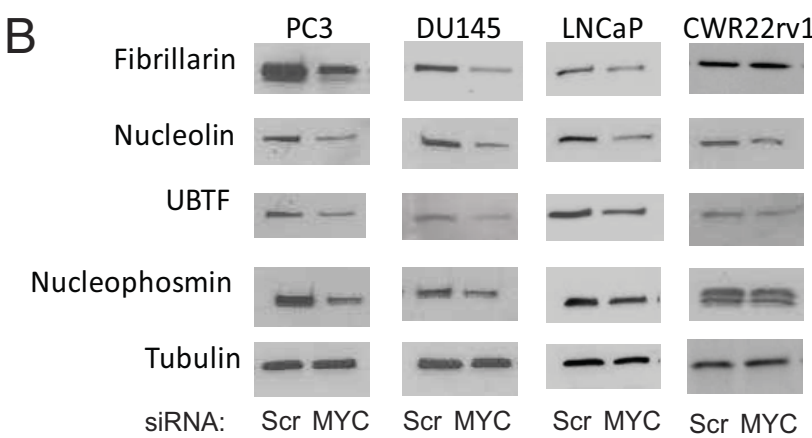
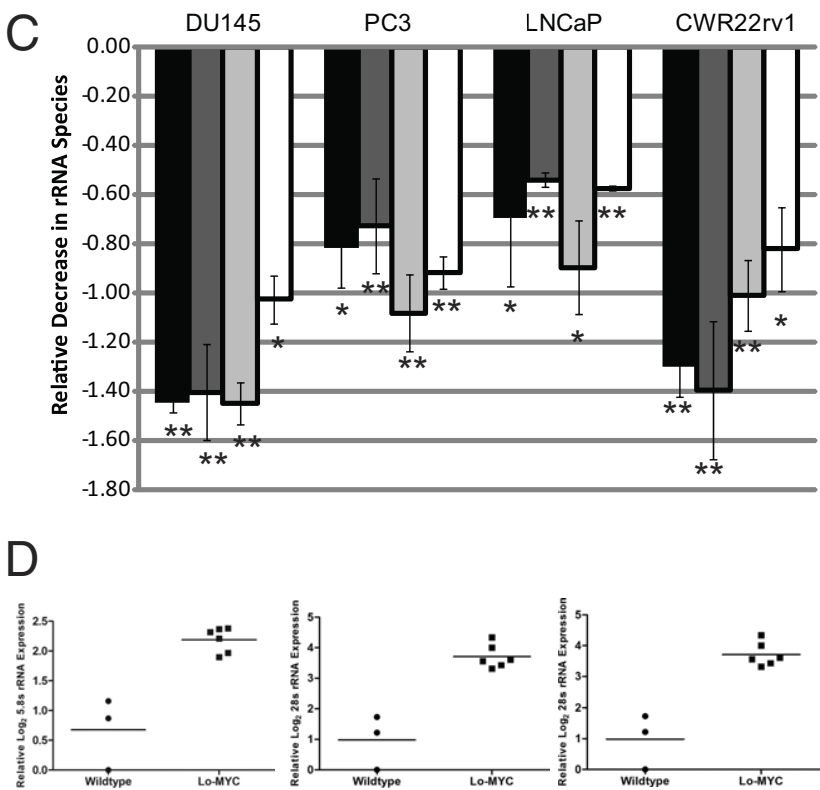

Figure 2. MYC regulates the expression of nucleolar genes, and nucleolar function in prostate cancer cells. A: Genome-wide mRNA expression changes were assessed 48 hours after MYC knockdown in PC3, DU145, and LNCaP cells using Agilent's 44k whole-genome array platform. GSEA was applied based on pathways and biological categories defined by GO, with a false discovery rate cutoff of $1 \%$ for significance. Selected categories (eg, all three cell types affected, two different types affected but the other not affected, etc.) of enriched gene sets after $M Y C$ knockdown are shown. B: Western blots showing decreased expression of several nucleolar proteins after transfection with siRNA targeting MYC, or control scrambled siRNA (Scr). Tubulin, whose expression is not MYC responsive, was used as a loading control. C: The relative decrease in the levels of pre-rRNA (black bars), $5.8 s$ rRNA (dark grey bars), 18s rRNA (grey bars), and 28s (white bars) rRNA were quantified by real-time PCR after siRNA-mediated MYC knockdown. Data were $\log _{2}$ transformed, and error bars show the SD of three independent experiments. ${ }^{*} P<0.03,{ }^{* *} P<0.01$. D: Elevated expression of 5.8 s rRNA, 18 s rRNA, and $28 \mathrm{~s}$ rRNA in Lo-MYC mice, as compared to wild-type controls.

in vivo, and is also required for sustained maintenance of nucleolar number and distribution in established human prostate cancer cell lines. The fact that nucleolar number and dispersion were reduced after forced reductions in MYC in vitro indicates that MYC affects nucleolar architecture even in established cancer cell lines. The finding that overall nucleolar size did not become markedly reduced after MYC knockdown in these cells may indicate that although MYC overexpression is sufficient to establish nucleolar hypertrophy initially in normal prostatic luminal cells in vivo, it is not solely responsible for maintaining overall nucleolar size in established advanced cancer cells.

\section{MYC Regulates Nucleolar Programs of Gene Expression in Prostate Cancer Cells}

To gain further functional insight into the mechanisms by which MYC regulates prostate cancer cell biology, we performed genome-wide mRNA expression analysis on
LNCaP, PC3, and DU145 cells after siRNA-mediated depletion of MYC. We applied GSEA, based on pathways and biological categories defined by the GO and KEGG databases. As expected, a large number of cellular processes were altered in a statistically significant manner, including processes relating to DNA replication, cell division, mitochondrial function, and various metabolic processes (Figure 2A, see Supplemental Figure S3; Table S1, A-F, at http://ajp.amjpathol.org). ${ }^{17,33}$

In terms of nucleolar activity, after MYC knockdown in LNCaP, DU145, and PC3 cells, a set of 133 genes that are associated with the nucleolus (GO:0005730) and 64 genes that are associated with rRNA processing (GO: 0006364) were coordinately regulated (see Supplemental Table S2, A and B, at http://ajp.amjpathol.org) $(P<$ $\left.10^{-10}\right)$. We verified a number of these changes at the protein level, including fibrillarin, nucleolin, UBF, and nucleophosmin, by Western blotting (Figure 2B). On examination of genes shown previously to be regulated by 
MYC in the prostate lesions from Hi-MYC mice, ${ }^{25}$ a number of genes related to nucleolar and ribosomal function were indeed increased (see Supplemental Table S2C at http://ajp.amjpathol.org). This indicates that in addition to the requirement for MYC to regulate programs of gene expression related to nucleolar and ribosomal function in established cancer cell lines, MYC overexpression in prostate epithelial cells can drive enhanced nucleolar and ribosomal gene expression de novo.

\section{MYC Is Required for rRNA Transcription and Processing}

A number of studies have shown that MYC can positively regulate the transcription and processing of rRNA in various tissue types. ${ }^{31,39,40}$ Using real-time quantitative PCR 48 hours after MYC knockdown, we quantified the expression of the $45 \mathrm{~S}$ precursor rRNA, which is very short lived and hence a sign of new transcription, as well as the mature rRNA products that are processed from this precursor: 28S, 18S, and 5.8S rRNA. There was a reduction in the pre-rRNA, as well as the processed rRNA species: 28S, 18S, and 5.8S, after siRNA-mediated knockdown of MYC ( $P<0.03$ for all) (Figure 2C). Next, we isolated RNA from six Lo-MYC mice and three wild-type control mice and found elevated expression of 5.8S, 18S, and 28S rRNA in the Lo-MYC mice $(P<0.001$ for $5.8 S$ and $28 S$ rRNA, $P=0.02$ for $18 \mathrm{~S} r R N A$ ) (Figure 2D).

\section{MYC Binds to the 5' Upstream Region of FBL}

To explore whether the changes in genes associated with nucleolar function observed by knockdown of MYC were a direct consequence of MYC transcriptional effects, we examined whether MYC is recruited to the promoter of a key component of this nucleolar program. Fibrillarin protein (encoded by the FBL gene), a highly conserved nucleolar protein, ${ }^{41}$ was previously identified as a MYCresponsive gene by microarray-based expression profiling. ${ }^{31,40}$ As compared to their wild-type counterparts, the Lo-MYC mice had elevated fibrillarin protein (Figure $3 \mathrm{~A}$ ) and mRNA $(P<0.005)$ expression (Figure 3B). The number of nucleoli per nucleus also increased in many of the mouse PIN cells (Figure 3A). Further, by quantitative realtime PCR and Western blotting, we confirmed that MYC regulates fibrillarin mRNA and protein expression in all four human prostate cancer cell lines, and in the mouse MYC-CaP cell line $(P<0.005)$ (Figures $2 \mathrm{~B}$ and $3 \mathrm{C}$ ). Although MYC has been shown to regulate FBL mRNA levels, ${ }^{31,40}$ the mechanism by which it does this has not been examined. Since the region immediately upstream of $F B L$ contains a $C p G$ island, it is likely that this region represents the $F B L$ promoter. Further, since this region contains an $E$ box, we hypothesized that MYC may be a direct transcriptional regulator of $F B L$ by binding to this region. Using ChIP, we found that MYC binds directly to the $5^{\prime}$ upstream region of $F B L$ in the prostate cancer cells PC3 and LNCaP (Figure 3D and Supplemental Figure S4A at http://ajp.amjpathol.org). Similar results were obtained in a B cell lymphoma cell line, P493, and the human embryonic stem cell line H9 (Figure 3D). As negative controls, we performed immunoprecipitation with a control IgG in place of the antibody against MYC, and also amplified a region previously shown to be negative for MYC binding ${ }^{42}$ (Figure 3D). As a positive control for MYC-ChIP, we have found that in PC3 cells, MYC binds to the rDNA promoter region, ${ }^{43}$ a known MYC target (M. Uemura, A.M. De Marzo, unpublished observations). Further, in publicly available ChIP-Seq UCSC Genome Browser data, MYC also bound specifically with a definite peak in the vicinity of the presumptive $F B L$ promoter region in lymphoblastoid B cells, K562, Hela, HepG2, and HUVEC (see Supplemental Figure S4B at http://ajp. amjpathol.org). In a separate study using global nuclear run-on assays, ${ }^{44}$ it was shown that an increased rate of transcription in response to MYC activation accounts for the elevated total FBL mRNA levels (see Supplemental Figure S4C at http://ajp.amjpathol.org).

The small nucleolar RNP complex that catalyzes the site-specific 2'-O methylation of rRNA is composed of four core proteins, encoded by FBL, NOL5A, NOP58, and NHP2L1, in addition to the small nucleolar RNAs (snoRNAs) ${ }^{45}$ Interestingly, microarray analysis showed that following MYC knockdown in all three prostate cancer cell lines tested, all of these genes were coordinately down-regulated (see Supplemental Table S2D at $h t t p: / /$ ajp.amjpathol.org).

\section{Fibrillarin Is Required for the Proliferation and Clonogenic Survival of Prostate Cancer Cells}

To begin to examine the functional significance of MYCdriven fibrillarin expression in prostate cancer, we used siRNA-mediated depletion of fibrillarin in the four human prostate cancer cell lines (Figure 4A). Depletion of fibrillarin markedly suppressed proliferation of all cell lines $(P<0.01$; see Supplemental Figure S4D at $h t t p: / /$ ajp.amjpathol.org). Further, in all cell lines, including CWR22Rv1, the clonogenic survival after fibrillarin knockdown was reduced by more than $80 \%(P<0.01$; Figure $4 \mathrm{~B})$. As previously reported in HeLa cells, there was no reduction in DNA synthesis, as measured by pulsed EdU incorporation, in cells after fibrillarin knockdown (see Supplemental Figure S4E at $h$ ttp://ajp.amjpathol.org). Further, there were no signs of apoptosis. These results are consistent with $a G_{2}$ or $M$ phase arrest as a result of loss of function of fibrillarin.

\section{Fibrillarin Is Required for rRNA Production and Processing in Prostate Cancer Cells}

Nop1, the yeast homolog to mammalian fibrillarin, is known to be required for the proper execution of a number of steps involved in pre-rRNA processing. ${ }^{46}$ We quantified the expression of 45S, 28S, 18S, and 5.8S rRNA by real-time PCR 48 hours following fibrillarin knockdown. We observed a slight reduction in the 45S pre-rRNA ( $P=$ not significant), and a reduction in its downstream maturation cleavage 
A

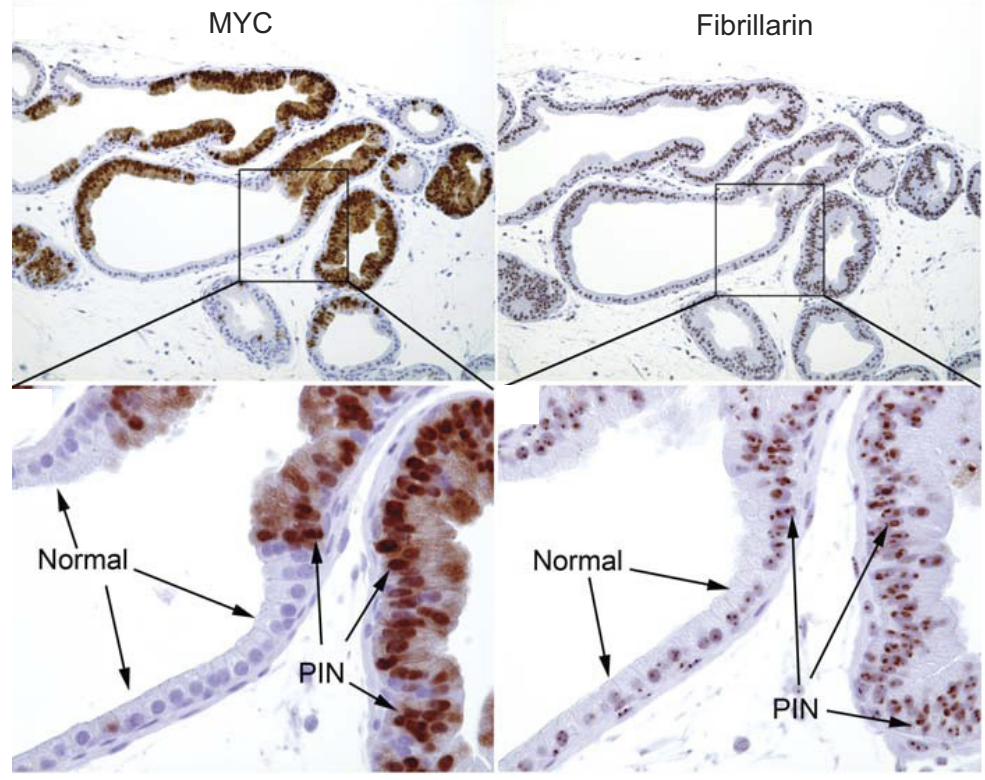

Figure 3. MYC regulates fibrillarin expression in prostate cancer cells. A: Fibrillarin protein overexpression correlates with MYC protein overexpression in Lo-MYC mice. Upper left panel, medium power (original magnification, $\times 100$ ) view of Lo-MYC mouse showing a region containing mixed PIN and normal glands. MYC staining occurs only in PIN cells. Upper right panel, medium power view of an adjacent section of that in upper left panel, showing heterogeneous staining for fibrillarin that corresponds well with regions of MYC staining in upper left panel. Lower panels are higher power views (original magnification, $\times 400$ ) corresponding to boxed areas in upper panels. Note the correspondence between fibrillarin overexpression and MYC staining. Note also that, as expected, fibrillarin staining occurs predominantly in subnuclear structures consistent with nucleoli, which are markedly enlarged in cells staining positive for MYC. B: Elevated fibrillarin mRNA expression Lo-MYC mice, as compared to wild-type controls. C: Decrease in fibrillarin mRNA following $M Y C$ knockdown. Data were $\log _{2}$ transformed, and error bars show the SD of three independent experiments. ${ }^{* *} P<0.005$. D: ChIP was performed on PC3, LNCaP, P493, and H9 embryonic stem cells using an antiMYC antibody (black bars) or an IgG control (white bars). A region upstream of the $F B L$ gene, as well as a known negative control region were amplified by quantitative real-time PCR.
B

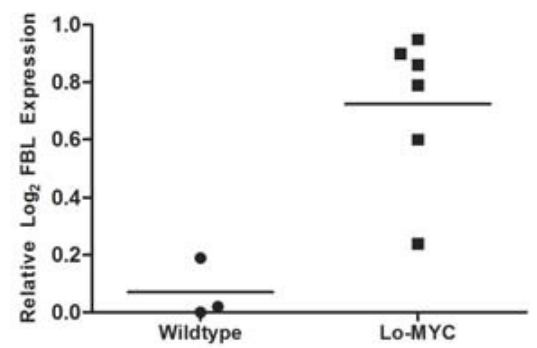

C

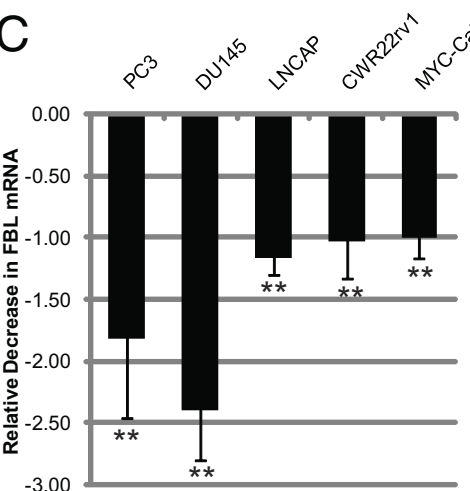

D

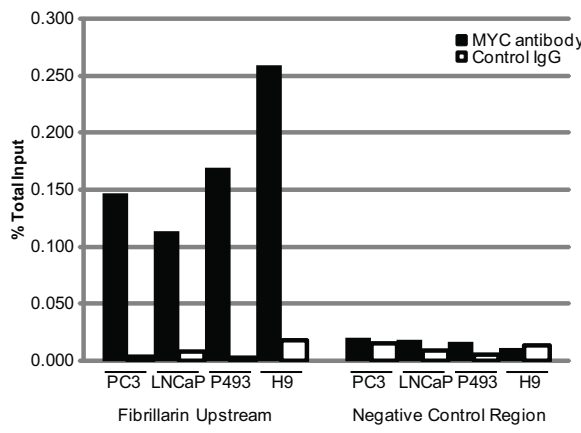

products ( $P<0.04$ for all) (Figure 4C), indicating that fibrillarin is indeed required for proper rRNA production/maturation in human prostate cancer cells. The lack of a significant reduction in the $45 \mathrm{~S}$ precursor rRNA was not unexpected, as fibrillarin has no known effects on transcription initiation. Fibrillarin knockdown also resulted in de- creased nucleolar number, similar to that of MYC knockdown, as visualized by AgNOR staining (see Supplemental Figure S2B at $h$ ttp://ajp.amjpathol.org). Hence, the role of MYC in regulating nucleolar architecture and activity can be attributed, at least in part, to the functions of its target gene, fibrillarin.
A

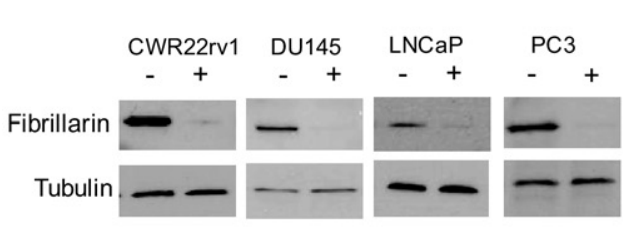

B

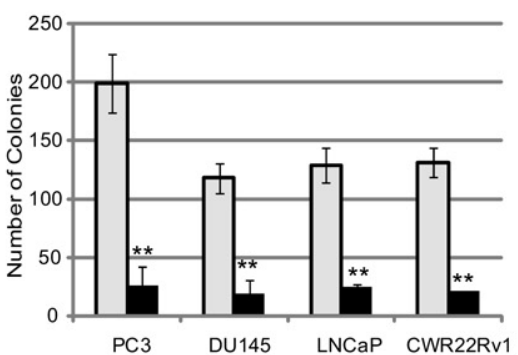

C

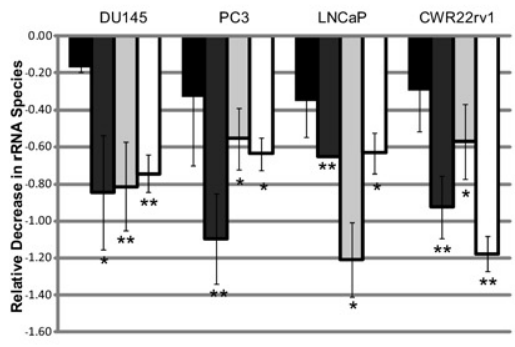

Figure 4. Fibrillarin is required for prostate cancer cells proliferation, and proper rRNA processing. A: Efficacy of siRNA-mediated fibrillarin knockdown $(+)$ in CWR22rv1, LNCaP, DU145, and PC3 prostate cancer cell lines was verified by Western blotting. Cells were transfected with a nontargeting siRNA pool as a control (-). B: In clonogenic survival assays, colony formation was measured in cells transfected with fibrillarin siRNA (black bars), or cells transfected with control siRNA. Error bars represent the SD of three independent experiments. C: The relative decrease in the levels of pre-rRNA (black bars), $5.8 s$ rRNA (dark grey bars), 18s rRNA (grey bars), and 28s (white bars) rRNA were quantified by real-time PCR after fibrillarin knockdown with siRNA. Data were log 2 transformed, and error bars show the SD of three independent experiments. ${ }^{*} P<0.04,{ }^{* *} P<0.01$. 
Fibrillarin Is Overexpressed in Prostate Adenocarcinoma, PIN, and Proliferative Inflammatory Atrophy

To determine the potential relevance of fibrillarin to human prostate cancer, we assessed its expression in clinical samples from prostate cancer patients. First, we isolated total RNA from 21 fresh-frozen prostate tumor and normal pairs, and using quantitative real-time RT-PCR, we found that FBL was overexpressed at the MRNA level in most cases tested (Figure 5A). Next, we isolated total protein from matched fresh-frozen normal and cancerous prostate tissue specimens and found that fibrillarin protein expression was elevated in the tumor samples by Western blotting (Figure 5B). We next expanded the number of cases and tissue types examined for fibrillarin protein by immunohistochemical staining and semiquantitative image analysis on TMAs (Figure 5, C-E, see Supplemental Table S3, A and B, at http://ajp.amjpathol.org). In normal epithelium, fibrillarin was generally stronger in the basal cells than in luminal cells (Figure 5, C and D, see Supplemental Table S3B at http://ajp.amjpathol.org). In normal luminal cells, and in stromal cells, fibrillarin protein was localized primarily to nucleoli, as expected. However, in normal basal cells, staining was both nucleolar as well as nucleoplasmic.

Compared to normal prostate epithelium, most cases of PIN showed elevated fibrillarin expression $(P<0.0001$, Figure 5, C and E, see Supplemental Table S3B at $h t t p: / /$ ajp.amjpathol.org). Both nucleolar and nucleoplasmic staining was observed in PIN cells. In primary prostate cancer lesions, the majority of cases showed elevated levels of fibrillarin expression in both the nucleoli and nucleoplasm (Figure 5, D and E). Also, in metastatic carcinoma cases, fibrillarin was significantly elevated as compared to that of normal prostate epithelium (Figure 5E, see Supplemental Figure S5A at http://ajp.amjpathol. org). We also found a correlation between the overall levels of MYC and fibrillarin proteins $(P<0.0001$, see Supplemental Figure S5B, Table S3C at http://ajp. amjpathol.org). These results are consistent with the hypothesis that MYC regulates fibrillarin mRNA and protein levels in clinical prostate tissues.

\section{Discussion}

We provide rigorous experimental evidence that links MYC to the activation of transcriptional modules associated with nucleolar function in prostate cancer. In addition, the activation of MYC in mouse prostatic luminal epithelial cells in vivo corresponds with a marked increase in nucleolar size and number, which we have now shown unequivocally by electron microscopy. Further, in human prostate cancer cell lines, forced reductions in MYC levels result in decreased nucleolar number and decreased nucleolar dispersion. There are other oncogenic lesions that occur in prostate cancer, such as PTEN loss or activation of Ets family transcription factors, which could affect nucleolar size and function. However, given that genetically engineered mice that overexpress ETV1 or that have lost Pten show, at most, modest effects on nucleoli, ${ }^{7-10}$ and that in most cases, alterations in Ets family members or Pten are clearly linked to later disease stages than PIN in humans, ${ }^{11-13}$ our findings suggest that MYC overexpression is largely responsible for increased nucleolar size and number in PIN, and early prostate cancer lesions in the majority of cases.

Cancer cell growth (as in mass) and replication require sustained high levels of protein synthesis and ribosome production. ${ }^{16}$ The importance of these processes in cancer is further highlighted by the findings that a number of oncogenic and tumor suppressive pathways, including PI3K, RAS, and MAPK, converge directly on the protein translational control machinery, and some translation initiation factors and ribosomal proteins are themselves oncogenic. ${ }^{15,16}$ Ribosome production requires, not only increased ribosomal protein production, but also high levels of rRNA synthesis, post-transcriptional processing of primary rRNA transcripts, pseudouridylation, and $2^{\prime}-\mathrm{O}$ methylation. rRNA transcription, processing and pre-ribosome assembly occur strictly within the nucleolus. ${ }^{14} \mathrm{~A}$ potential link, therefore, between increased protein synthesis and cancer comes from the long-known finding that morphologically enlarged, "prominent" nucleoli and increased numbers of nucleoli are present in cancer cells from many different organ systems. ${ }^{2,16}$ Although control of translation is a critical pathway that is the subject of large efforts in terms of drug development, comparatively little effort has been focused on upstream events such as rRNA transcription and posttranscriptional processing, including rRNA methylation and pseudouridylation, as potential drug development targets. In the present study, we found that fibrillarin is required for proliferation and self-renewal of prostate cancer cells, and is directly bound by MYC in its presumptive promoter region, suggesting it is a direct MYC target gene. Further, using global nuclear run-on assays, ${ }^{44}$ the elevated FBL mRNA was shown to be a direct transcriptional response to MYC activation. Although these results do not reveal the detailed mechanisms regarding how MYC recruitment to the FBL promoter stimulates transcription, future studies should determine what other proteins are recruited by MYC, what histone modifications may occur, and whether MYC directly stimulates initiation, relieves promoter pausing, or both. We also found that fibrillarin mRNA and protein are overexpressed in mouse and human PIN and human adenocarcinoma lesions, and that levels of fibrillarin protein correlate with levels of MYC protein in vivo.

As part of the C/D nucleolar small nuclear ribonucleoprotein particle (RNP), fibrillarin is required for multiple steps in rRNA processing, and is the catalytic subunit that, in conjunction with sno-RNAs, is responsible for site-specific $2^{\prime}-\mathrm{O}$ methylation of rRNA. ${ }^{46,47}$ Fibrillarin is required for yeast cell viability, ${ }^{46}$ and mice that are homozygous null for $F B L$ do not develop past the morula stage. ${ }^{48}$ In terms of cancer, only a few studies have examined fibrillarin. In one study, it was shown that siRNA-mediated knockdown of fibrillarin in HeLa cells resulted in decreased proliferation and changes in nuclear structure. ${ }^{49}$ In clinical samples, a recent study reported an up-regulation of fibrillarin mRNA in human 
A

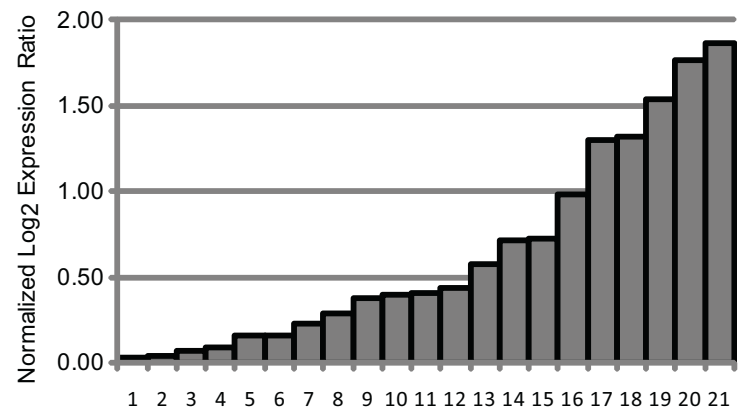

\section{C}

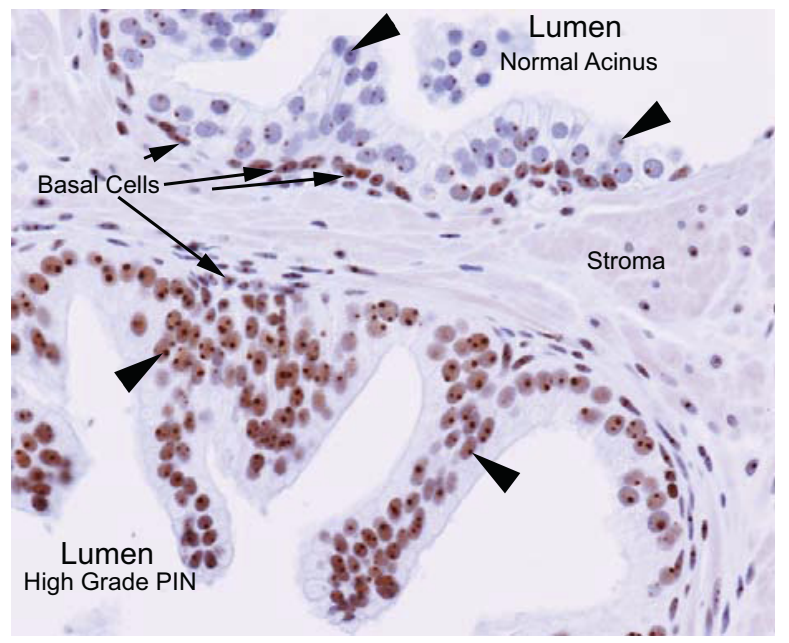

$\mathrm{E}$

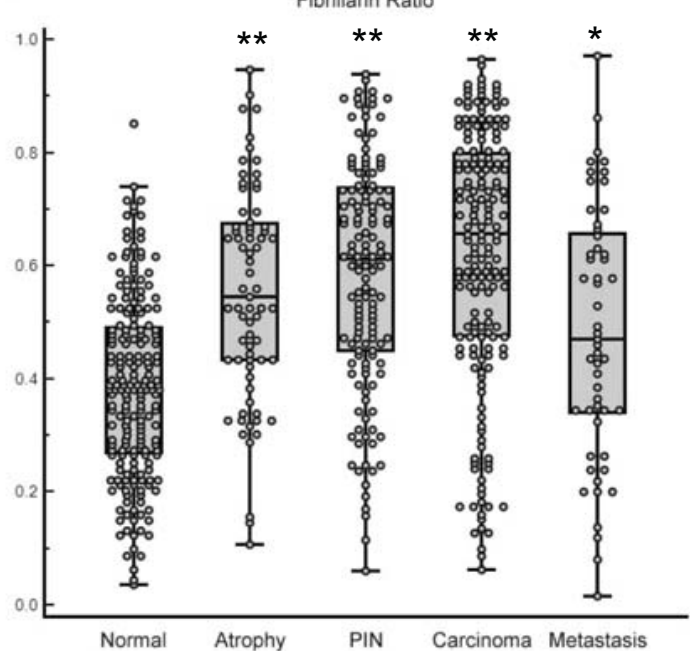

B
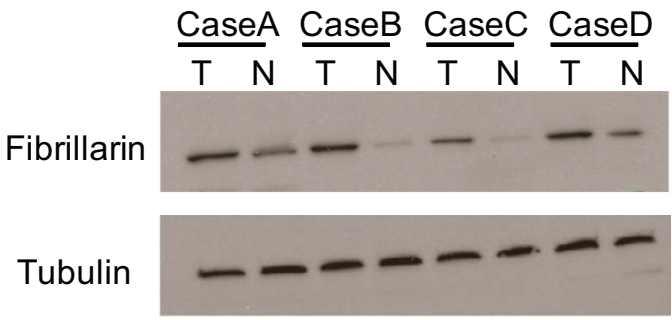

$\mathrm{D}$

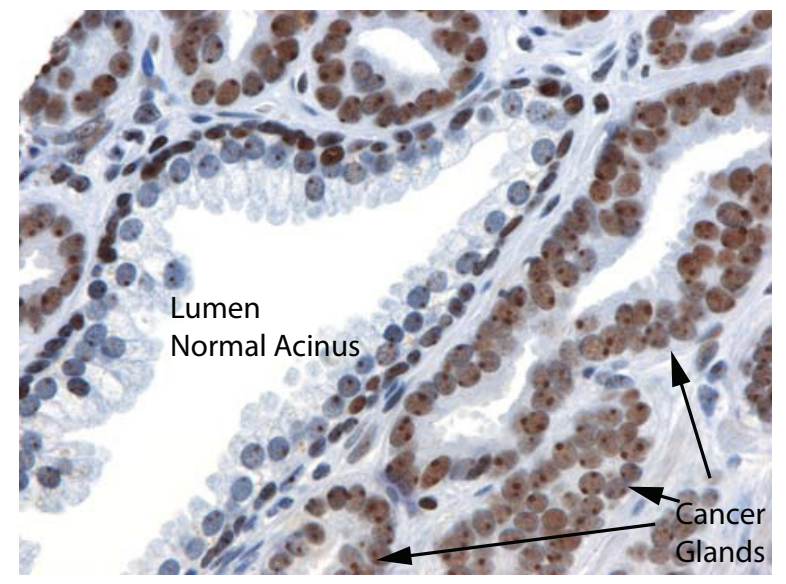

Figure 5. Fibrillarin is elevated in prostate adenocarcinoma, PIN, and proliferative inflammatory atrophy. A: Elevated fibrillarin mRNA expression in primary prostate cancer tissues, as compared to matched normal prostate tissue. FBL expression in prostate cancer tissues was measured by quantitative real-time PCR and normalized to TBP, and matched normal tissue. B: Western blot showing total fibrillarin expression in matched normal $(\mathrm{N})$ and tumor (T) prostate tissues. C: Fibrillarin protein expression is elevated in PIN. D: Fibrillarin protein expression is elevated in a primary prostate cancer lesion. E: Combined dot plot and box-and-whisker graph of the fibrillarin nuclear area ratio of normal prostate glands, atrophy, PIN, and primary and metastatic carcinoma. Each dot represents the average score from all TMA cores for a given diagnosis from a single patient. ${ }^{*} P<0.005,{ }^{* *} P<0.001$.

squamous cell cervical carcinoma specimens. ${ }^{50}$ However, fibrillarin has not been studied in prostate cancer, and a functional role for fibrillarin has not been systematically studied in any cancer previously. Taken together with the finding that fibrillarin is required for prostate cancer cell proliferation, these results suggest that the rRNA 2'-O methyltransferase activity of fibrillarin could potentially be exploited as a novel cancer drug target.

There are other implications for the finding that MYC regulates a nucleolar program of gene expression in prostate cancer. For example, in a separate study, it was

found that MYC regulates a core set of genes in a number of cell types including lymphoma, colonic carcinoma, as well as mouse and human embryonic stem cells $(\mathrm{H}$. Ji, G. Wu, K.I. Zeller, C.V. Dang, unpublished data). This gene signature was highly enriched for genes involved in ribosome biogenesis, suggesting the importance of MYCdriven cell growth in stem cells and cancer cells. These results could, therefore, shed light on the critical question of the cell of origin (eg, tumor-initiating cells) in prostate cancer. For example, cancer is often considered a "stem cell" disease, implying that tissue stem cells are the target of tumor-initiating cell/cancer stem cell formation. Yet, 
the cell of origin that is the target for neoplastic transformation in the prostate remains controversial. ${ }^{51,52} \mathrm{Al}$ though most evidence implicates the basal cells as containing the prostate stem cells, the phenotype of PIN and invasive prostate cancer cells is most similar to the "terminally" differentiated luminal cells. A recent study indicated that a rare subpopulation of luminal stem-like cells found in mouse prostate epithelium is capable of becoming a tumor-initiating cell may shed light on this discrepancy, ${ }^{52}$ although another recent study indicated that basal cells themselves could become tumor-initiating cells. ${ }^{51}$ However, there is yet another possibility raised by the fact that MYC is commonly overexpressed in PIN cells. Wong et al recently reported that MYC regulates a set of gene modules that are present in embryonic stem cells and that are not present in most tissue stem cells. ${ }^{53}$ In our preliminary data, we find that MYC indeed regulates this module of genes in human prostate cancer cells (C.M. Koh, S. Yegnasubramanian, C.V. Dang, M. Aryee, A.M. De Marzo, unpublished observations). Taken together with the following findings that: (i) a common core set of genes related to nucleolar function and ribosome biogenesis (including FBL) is regulated by MYC in mouse and human embryonic stem cells; (ii) MYC overexpression alone can apparently transform large numbers mouse prostate luminal cells in a single step; ${ }^{25,26}$ and that (iii) MYC is a key factor in reprogramming of adult mature cell types into induced pluripotent stem cells, we suggest the novel hypothesis that MYC overexpression may activate a program of self-renewal, used normally by embryonic stem cells, perhaps in partially differentiated progenitor cells or even in fully differentiated prostatic luminal cells, that can lead to PIN and, ultimately, invasive prostate carcinoma. Although this hypothesis requires additional testing, it implies that one may not need to invoke the transformation of prostatic stem cells as tumor initiating cells in prostate cancer.

In summary, the current results show that MYC is a mediator of programs of gene expression directly linked to altered nucleolar size, number and function in prostate cancer cells and provide a molecular explanation for these hallmark changes in PIN and invasive prostate cancer lesions. Further, we identify the nucleolar protein fibrillarin as a MYC target that is overexpressed in prostate cancer and that is required for proliferation of human prostate cancer cells.

\section{Acknowledgments}

We thank Michael Delannoy of the Johns Hopkins School of Medicine Microscope facility for performing tissue handling, staining and help with all aspects of the mouse TEM studies. We thank Wayne Yu and Haihua Chu for technical assistance. Helen Fedor, Marcela Southerland, Kristen Lecksell, and the Brady Urological Institute Prostate Specimen Repository helped prepare fresh prostate tissues and tissue microarrays.

\section{References}

1. Derenzini M, Montanaro L, Trere D: What the nucleolus says to a tumour pathologist. Histopathology 2009, 54:753-762

2. Derenzini M, Trere D, Pession A, Montanaro L, Sirri V, Ochs RL: Nucleolar function and size in cancer cells. Am J Pathol 1998, 152: 1291-1297

3. Scholl AJ: Histology and mortality in tumors of the prostate, bladder, and kidney. Cal West Med 1927, 26:185-189

4. Bostwick DG, Pacelli A, Lopez-Beltran A: Molecular biology of prostatic intraepithelial neoplasia. Prostate 1996, 29:117-134

5. Hansen AB, Ostergard B: Nucleolar organiser regions in hyperplastic and neoplastic prostatic tissue. Virchows Arch A Pathol Anat Histopathol 1990, 417:9-13

6. Fischer AH, Bardarov S Jr., Jiang Z: Molecular aspects of diagnostic nucleolar and nuclear envelope changes in prostate cancer. $J$ Cell Biochem 2004, 91:170-184

7. Tomlins SA, Laxman B, Dhanasekaran SM, Helgeson BE, Cao X, Morris DS, Menon A, Jing X, Cao Q, Han B, Yu J, Wang L, Montie JE, Rubin MA, Pienta KJ, Roulston D, Shah RB, Varambally S, Mehra R, Chinnaiyan AM: Distinct classes of chromosomal rearrangements create oncogenic ETS gene fusions in prostate cancer. Nature 2007, 448:595-599

8. Carver BS, Tran J, Chen Z, Carracedo-Perez A, Alimonti A, Nardella C, Gopalan A, Scardino PT, Cordon-Cardo C, Gerald W, Pandolfi PP: ETS rearrangements and prostate cancer initiation, Nature 2009, 457:E1; discussion E2-E3

9. Shin S, Kim TD, Jin F, van Deursen JM, Dehm SM, Tindall DJ, Grande JP, Munz JM, Vasmatzis G, Janknecht R: Induction of prostatic intraepithelial neoplasia and modulation of androgen receptor by ETS variant 1/ETS-related protein 81. Cancer Res 2009, 69:8102-8110

10. Klezovitch O, Risk M, Coleman I, Lucas JM, Null M, True LD, Nelson PS, Vasioukhin V: A causal role for ERG in neoplastic transformation of prostate epithelium, Proc Natl Acad Sci U S A 2008, 105:21052110

11. Park K, Tomlins SA, Mudaliar KM, Chiu YL, Esgueva R, Mehra R, Suleman K, Varambally S, Brenner JC, MacDonald T, Srivastava A, Tewari AK, Sathyanarayana U, Nagy D, Pestano G, Kunju LP, Demichelis F, Chinnaiyan AM, Rubin MA: Antibody-based detection of ERG rearrangement-positive prostate cancer. Neoplasia 2010, 12: 590-598

12. Furusato B, Tan SH, Young D, Dobi A, Sun C, Mohamed AA, Thangapazham R, Chen $Y$, McMaster $G$, Sreenath $T$, Petrovics G, McLeod DG, Srivastava S, Sesterhenn IA: ERG oncoprotein expression in prostate cancer: clonal progression of ERG-positive tumor cells and potential for ERG-based stratification, Prostate Cancer Prostatic Dis 2010, 13:228-237

13. Yoshimoto M, Cutz JC, Nuin PA, Joshua AM, Bayani J, Evans AJ, Zielenska M, Squire JA: Interphase FISH analysis of PTEN in histologic sections shows genomic deletions in $68 \%$ of primary prostate cancer and $23 \%$ of high-grade prostatic intra-epithelial neoplasias. Cancer Genet Cytogenet 2006, 169:128-137

14. Boisvert FM, van Koningsbruggen S, Navascues J, Lamond Al: The multifunctional nucleolus. Nat Rev Mol Cell Biol 2007, 8:574-585

15. Montanaro L, Trere D, Derenzini M: Nucleolus, ribosomes, and cancer. Am J Pathol 2008, 173:301-310

16. Ruggero D, Pandolfi PP: Does the ribosome translate cancer?. Nat Rev Cancer 2003, 3:179-192

17. Meyer N, Penn LZ: Reflecting on 25 years with MYC. Nat Rev Cancer 2008, 8:976-990

18. Jenkins RB, Qian J, Lieber MM, Bostwick DG: Detection of c-myc oncogene amplification and chromosomal anomalies in metastatic prostatic carcinoma by fluorescence in situ hybridization. Cancer Res 1997, 57:524-531

19. Bova GS, Isaacs WB: Review of allelic loss and gain in prostate cancer. World J Urol 1996, 14:338-346

20. Buttyan R, Sawczuk IS, Benson MC, Siegal JD, Olsson CA: Enhanced expression of the c-myc protooncogene in high-grade human prostate cancers. Prostate 1987, 11:327-337

21. Fleming $W H$, Hamel A, MacDonald R, Ramsey $E$, Pettigrew NM, Johnston B, Dodd JG, Matusik RJ: Expression of the c-myc protooncogene in human prostatic carcinoma and benign prostatic hyperplasia. Cancer Res 1986, 46:1535-1538 
22. Gurel B, Iwata T, Koh CM, Jenkins RB, Lan F, Van Dang C, Hicks JL, Morgan J, Cornish TC, Sutcliffe S, Isaacs WB, Luo J, De Marzo AM: Nuclear MYC protein overexpression is an early alteration in human prostate carcinogenesis. Mod Pathol 2008, 21:1156-1167

23. Gil J, Kerai P, Lleonart M, Bernard D, Cigudosa JC, Peters G, Carnero A, Beach D: Immortalization of primary human prostate epithelial cells by c-Myc. Cancer Res 2005, 65:2179-2185

24. Williams K, Fernandez S, Stien X, Ishii K, Love HD, Lau YF, Roberts $\mathrm{RL}$, Hayward SW: Unopposed c-MYC expression in benign prostatic epithelium causes a cancer phenotype. Prostate 2005, 63:369-384

25. Ellwood-Yen K, Graeber TG, Wongvipat J, Iruela-Arispe ML, Zhang J, Matusik R, Thomas GV, Sawyers CL: Myc-driven murine prostate cancer shares molecular features with human prostate tumors. Cancer Cell 2003, 4:223-238

26. Iwata T, Schultz D, Hicks J, Hubbard GK, Mutton LN, Lotan TL, Bethel C, Lotz MT, Yegnasubramanian S, Nelson WG, Dang CV, Xu M, Anele U, Koh CM, Bieberich CJ, De Marzo AM: MYC overexpression induces prostatic intraepithelial neoplasia and loss of Nkx3.1 in mouse Iuminal epithelial cells. PLoS One 2010, 5:e9427

27. Grewal SS, Li L, Orian A, Eisenman RN, Edgar BA: Myc-dependent regulation of ribosomal RNA synthesis during Drosophila development. Nat Cell Biol 2005, 7:295-302

28. Kim S, Li Q, Dang CV, Lee LA: Induction of ribosomal genes and hepatocyte hypertrophy by adenovirus-mediated expression of CMyc in vivo, Proc Natl Acad Sci U S A 2000, 97:11198-11202

29. Dai MS, Lu H: Crosstalk between C-Myc and ribosome in ribosomal biogenesis and cancer. J Cell Biochem 2008, 105:670-677

30. Ruggero D: The role of Myc-induced protein synthesis in cancer. Cancer Res 2009, 69:8839-8843

31. Schlosser I, Holzel M, Murnseer M, Burtscher H, Weidle UH, Eick D: A role for $\mathrm{c}-\mathrm{Myc}$ in the regulation of ribosomal RNA processing. Nucleic Acids Res 2003, 31:6148-6156

32. van Riggelen J, Yetil A, Felsher DW: MYC as a regulator of ribosome biogenesis and protein synthesis. Nat Rev Cancer 2010, 10:301-309

33. Zeller KI, Jegga AG, Aronow BJ, O'Donnell KA, Dang CV: An integrated database of genes responsive to the Myc oncogenic transcription factor: identification of direct genomic targets. Genome Biol 2003, 4:R69

34. Watson PA, Ellwood-Yen K, King JC, Wongvipat J, Lebeau MM, Sawyers CL: Context-dependent hormone-refractory progression revealed through characterization of a novel murine prostate cancer cell line. Cancer Res 2005, 65:11565-11571

35. Haffner MC, Aryee MJ, Toubaji A, Esopi DM, Albadine R, Gurel B, Isaacs WB, Bova GS, Liu W, Xu J, Meeker AK, Netto G, De Marzo AM Nelson WG, Yegnasubramanian S: Androgen-induced TOP2B-mediated double-strand breaks and prostate cancer gene rearrangements. Nat Genet 2010, 42:668-675

36. Cornish T, DeMarzo AM, Gurel B, Morgan J: FRIDA. An open source framework for image dataset analysis. Presented at the 12th Annual International Conference on Advancing Practice, Instruction and Innovation Through Informatics. 2007 September 9-12, Pittsburgh, PA

37. Wang H, Mannava S, Grachtchouk V, Zhuang D, Soengas MS, Gudkov AV, Prochownik EV, Nikiforov MA: c-Myc depletion inhibits proliferation of human tumor cells at various stages of the cell cycle. Oncogene 2008, 27:1905-1915
38. Trere D: AgNOR staining and quantification. Micron 2000, 31:127-131

39. Arabi A, Wu S, Ridderstrale K, Bierhoff H, Shiue C, Fatyol K, Fahlen S, Hydbring P, Soderberg O, Grummt I, Larsson LG, Wright AP: C-Myc associates with ribosomal DNA and activates RNA polymerase transcription. Nat Cell Biol 2005, 7:303-310

40. Coller HA, Grandori C, Tamayo P, Colbert T, Lander ES, Eisenman RN, Golub TR: Expression analysis with oligonucleotide microarrays reveals that MYC regulates genes involved in growth, cell cycle, signaling, and adhesion, Proc Natl Acad Sci U S A 2000, 97:3260-3265

41. Aris JP, Blobel G: cDNA cloning and sequencing of human fibrillarin, a conserved nucleolar protein recognized by autoimmune antisera Proc Natl Acad Sci U S A 1991, 88:931-935

42. Chang TC, Zeitels LR, Hwang HW, Chivukula RR, Wentzel EA, Dews M, Jung J, Gao P, Dang CV, Beer MA, Thomas-Tikhonenko A, Mendell JT: Lin-28B transactivation is necessary for Myc-mediated let-7 repression and proliferation. Proc Natl Acad Sci U S A 2009, 106: 3384-3389

43. Grandori C, Gomez-Roman N, Felton-Edkins ZA, Ngouenet C, Galloway DA, Eisenman RN, White RJ: c-Myc binds to human ribosoma DNA and stimulates transcription of rRNA genes by RNA polymerase I. Nat Cell Biol 2005, 7:311-318

44. Fan J, Zeller K, Chen YC, Watkins T, Barnes KC, Becker KG, Dang CV, Cheadle C: Time-dependent c-Myc transactomes mapped by Array-based nuclear run-on reveal transcriptional modules in human B cells. PLoS One 5:e9691

45. Bleichert F, Gagnon KT, Brown BA 2nd, Maxwell ES, Leschziner AE, Unger VM, Baserga SJ: A dimeric structure for archaeal box C/D small ribonucleoproteins. Science 2009, 325:1384-1387

46. Tollervey D, Lehtonen $H$, Carmo-Fonseca M, Hurt EC: The small nucleolar RNP protein NOP1 (fibrillarin) is required for pre-rRNA processing in yeast. EMBO J 1991, 10:573-583

47. Fatica A, Galardi S, Altieri F, Bozzoni I: Fibrillarin binds directly and specifically to U16 box C/D snoRNA. RNA 2000, 6:88-95

48. Newton K, Petfalski E, Tollervey D, Caceres JF: Fibrillarin is essential for early development and required for accumulation of an intronencoded small nucleolar RNA in the mouse. Mol Cell Biol 2003, 23:8519-8527

49. Amin MA, Matsunaga S, MA N, Takata H, Yokoyama M, Uchiyama S, Fukui K: Fibrillarin, a nucleolar protein, is required for normal nuclear morphology and cellular growth in HeLa cells. Biochem Biophys Res Commun 2007, 360:320-326

50. Choi YW, Kim YW, Bae SM, Kwak SY, Chun HJ, Tong SY, Lee HN, Shin JC, Kim KT, Kim YJ, Ahn WS: Identification of differentially expressed genes using annealing control primer-based GeneFishing in human squamous cell cervical carcinoma. Clin Oncol (R Coll Radiol) 2007, 19:308-318

51. Goldstein AS, Huang J, Guo C, Garraway IP, Witte ON: Identification of a cell of origin for human prostate cancer. Science 2010, 329:568-571

52. Wang $X$, Kruithof-de Julio M, Economides KD, Walker D, Yu H, Halili MV, Hu YP, Price SM, Abate-Shen C, Shen MM: A luminal epithelial stem cell that is a cell of origin for prostate cancer. Nature 2009, 461:495-500

53. Wong DJ, Liu H, Ridky TW, Cassarino D, Segal E, Chang HY: Module map of stem cell genes guides creation of epithelial cancer stem cells. Cell Stem Cell 2008, 2:333-344 